\title{
Expression of BRCA1 and ERCC1 as predictive clinical outcome after radiochemotherapy in patients with locoregionally moderate-advanced nasopharyngeal carcinoma
}

\author{
Shan $\mathrm{Xu}^{1{ }^{1,},}$, Yanxin Yu${ }^{1, *}$, Jinfeng Rong ${ }^{1}$, Defeng $\mathrm{Hu}^{1}$, LiJun Zhang ${ }^{2}$, Shaozhi Fu ${ }^{1}$, \\ Hongru Yang ${ }^{1}$, Juan Fan ${ }^{1}$, Linglin Yang ${ }^{1}$ and Jingbo $\mathbf{W u}^{1}$ \\ ${ }^{1}$ Department of Oncology, The Affiliated Hospital of Southwest Medical University, Luzhou 646000, P. R. China \\ ${ }^{2}$ Department of Otolaryngology Head and Neck Surgery, The Affiliated Hospital of Southwest Medical University, Luzhou \\ 646000 , P. R. China \\ *These authors have contributed equally to this work \\ Correspondence to: Jingbo Wu, email: wjb6147@163.com \\ Keywords: nasopharyngeal carcinoma, ERCC1, BRCA 1, induction chemotherapy, cisplatin \\ Received: July 13, $2016 \quad$ Accepted: January 26, $2017 \quad$ Published: February 21, 2017 \\ Copyright: Xu et al. This is an open-access article distributed under the terms of the Creative Commons Attribution License (CC-BY), \\ which permits unrestricted use, distribution, and reproduction in any medium, provided the original author and source are credited.
}

\section{ABSTRACT}

In this study, we examined ERCC1 and BRCA1 expression and clinical outcome of 201 phase-III-IV nasopharyngeal carcinoma patients who were treated with cisplatinbased induced chemotherapy and concurrent radiochemotherapy. The chemotherapy response rate of $\mathrm{BRCA1}^{-}$and $\mathrm{BRCA1}^{+}$patients was $73.6 \%$ and $55.8 \%$, respectively. In addition, the chemotherapy response rate of ERCC1- and ERCC1+ patients was $76.9 \%$ and $56.6 \%$, respectively. In patients' tissues, ERCC1 expression associated with BRCA1 expression. The chemotherapy response rate of BRCA1- and ERCC1patients was $(82.1 \%)$ and higher than that of other groups (range 52.4-73.1\%). The radiochemotherapy response rate of BRCA1- and ERCC1- patients was higher than that BRCA1 $^{+}$and ERCC1 ${ }^{+}$patients. BRCA1- and ERCC1- patients showed higher 3-year overall survival, failure-free survival, locoregional failure-free survival and distant failure-free survival compared to BRCA1 ${ }^{+}$or ERCC1 ${ }^{+}$patients. Moreover, the 3-year overall survival, failure-free survival and distant failure-free survival of the BRCA1- and ERCC1- group were higher than that of other groups. TNM stage, ERCC1 expression and the correlation between BRCA1 and ERCC1 expression seemed significant overall survival factors. In conclusion, in nasopharyngeal carcinoma patients, ERCC1 and BRCA1 may be a predictor of response to platinum-based chemotherapy and concurrent radiochemotherapy.

\section{INTRODUCTION}

According to epidemiology, therapeutic method and prognosis, nasopharyngeal carcinoma (NPC) is a special kind of cancer in head and neck [1]. Even if it is pretty uncommon in most parts of the world, NPC is a common malignancy in China [2]. The standard dose of radiotherapy (RT) is 65-75 GY within 6-7 weeks in consideration of that NPC is very sensitive to radio. Numerous patients with their disease at a locally advanced stage were treated by RT alone, comes out the overall survival (OS) in 5 years range from $32 \%$ to $52 \%$ [3]. However, high rates of local recurrence or metastasis has tremendous influence in patients with locally advanced NPC particularly, due to they are the relevant factors of conventional RT $[4,5]$.

To improve survival, people with locally advanced NPC were suggested to accept the chemotherapy as an additional treatment, which is well established for metastasis, with a high level of objective response, enduring remission and in some cases of long survival [6]. Platinum-based chemotherapy is the recognized first-line treatment for metastatic NPC [7]. The function of platinum anticancer medicine will lead to the transformation of DNA structure and inhibit DNA to replicate and transcript in the end, which is based on the formation of DNA adducts [8]. Therefore, as a possible factor in the DNA 
repair process, the expression of genes has been studied in patients who accepted the chemotherapy with platinum. The consideration of adopting a better chemotherapeutic regimen will cause the maximization of curative effects and the minimization of adverse effects, if the efficient bio markers for chemotherapy resistance are established [9].

The excision repair cross-complementing 1(ERCC1) can be explained as a protein in the nucleotide excision repair (NER) complex is encoded by a gene, hence a group of proteins would have the ability to repair DNA damage which caused by substance forming adducts, e.g., platinum [8]. Breast cancer 1(BRCA1) is another oncosuppressor gene that had two different DNA repair systems so-called NER and double-stranded break repair (DSBR). Several studies demonstrated that high expression of BRCA1 shows a marker of platinum resistance in non-small-cell lung cancer(NSCLC) [10].

Although suggested by above studies that both ERCC1 and BRCA1 might act as efficient bio markers for NSCLC and colorectal cancer patients' sensitivity in chemotherapy, knowledge on these biomarkers in NPC is still limited [11]. Moreover, it is currently not known if ERCC1 and BRCA1 are prognostic factors after concurrent radiochemotherapy treatment. Additionally, no analysis of previous research shows that these two factors have relevance with the treatment result and survival in the meantime. Therefore, we made the determination of expression of ERCC 1 and BRCA1 in NPC patients, and did some research about the relevance between expression of these genes and clinical result of NPC.

\section{RESULTS}

\section{Detection of ERCC1 and BRCA1 expression in NPC specimens}

Expression of BRCA1 and ERCC1 proteins was assessed by immunohistochemistry. We found that BRCA1 and ERCC1 proteins were located in the nuclei of cancer cells. BRCA1 positive expression $\left(\mathrm{BRCA}^{+}\right)$was detected in tumors of 129 patients, whereas 72 patients were negative for $\mathrm{BRCC} 1$ negative expression $\left(\mathrm{BRCA}^{-}\right)$ (Figure 1). There were 136 patients with positive expression of ERCC1 $\left(\mathrm{ERCC}^{+}\right)$and only 65 patients with ERCC1 negative expression (ERCC1 ${ }^{-}$) (Figure 1). In addition, ERCC1 and BRCA1 expression in different NPC groups was analyzed by real-time quantitative (Figure 1). Quantification of relative gene expression was counted in accordance with the relative $\mathrm{Ct}$ method using GAPDH as a control. In the negative group, median BRCA1 mRNA expression was 1.1 (range: 0.84-1.31). In the positive group median BRCA1 mRNA expression was 2.9 (range: 2.41-4.39). Median ERCC1 mRNA expression was 1.3 in the negative group (range: 0.96-1.81), whereas in the positive group it was 3.8 (range: $2.76-4.91$ ).

\section{Association of BRCA1 and ERCC1 expression with clinical pathological characteristics}

Patient characteristics are summarized in Table 1. Statistical analysis showed expression of BRCA1 was associated with age $(\mathrm{P}<0.05)$. However, other clinical pathological parameters such as sex, pathology classification, lymph node metastasis and TNM stage had no correlations with expression of BRCA1. Similarly, there was a statistically significant difference $(\mathrm{P}<0.05)$ in pathology classification was found in patients with expression of ERCC1. Other clinical parameters were not statistically significant.

\section{Correlation between BRCA1 and ERCC1 expression in patients with nasopharyngeal carcinoma}

Table 2 shows a significant correlation between BRCA1 and ERCC1 expression in patients with NPC (Spearman's test, $\mathrm{r}=0.348, \mathrm{P}<0.05$ ). All of the 201 patients included 103 patients were $\mathrm{BRCA}^{+}$and $\mathrm{ERCCl}^{+}, 39$ patients were $\mathrm{BRCA}^{-}$and $\mathrm{ERCC1}^{-}, 33$ patients were $\mathrm{BRCA}^{-}$and $\mathrm{ERCC}^{+}$and 26 patients were $\mathrm{BRCA}^{+}$and $\mathrm{ERCC1}^{-}$.

\section{Association of ERCC1 and BRCA1 expression with prognosis of patients with NPC after chemotherapy and concurrent chemoradiotherapy}

\section{Short-term outcomes}

Of the 201 cases included in this study, the shortterm outcomes in primary NPC and cervical lymph node after chemotherapy treatment are shown in Table 3. $\mathrm{BRCA}^{-}$patients had a higher response rate compared to $\mathrm{BRCA}^{+}$patients, $\mathrm{P}=0.013$. Similarly, $\mathrm{ERCC} 1^{-}$patients benefited more from chemotherapy than $\mathrm{ERCC} 1^{+}$ patients. Chemotherapy in the $\mathrm{ERCC1}^{-}$group had a higher response rate compared to the $\mathrm{ERCC} 1^{+}$group, $\mathrm{P}=0.005$. In addition, in primary $\mathrm{NPC}, \mathrm{BRCA}^{-}$and $\mathrm{ERCC1}^{-}$patients had the highest response rate compared to patients that were $\mathrm{BRCA}^{+}$and $\mathrm{ERCC}^{+}, \mathrm{BRCA}^{-}$and $\mathrm{ERCC}^{+}$and $\mathrm{BRCA}^{+}$and $\mathrm{ERCC}^{-}, \mathrm{P}=0.005$. In cervical lymph nodes, the efficacy of chemotherapy in the $\mathrm{BRCA}^{-}$group was higher than in the $B R C A 1^{+}$group $(\mathrm{P}=0.036)$. Moreover, the efficacy of chemotherapy in the $\mathrm{ERCC1}^{-}$group was significantly higher from that in the $\mathrm{ERCC}^{+}$group $(\mathrm{P}=0.019)$. In cervical lymph nodes, patients that were $\mathrm{BRCA}^{-}$and $\mathrm{ERCC1}^{-}$had a higher response rate compared to patients that were $\mathrm{BRCA}^{+}$and $\mathrm{ERCC}^{+}, \mathrm{BRCA}^{-}$and $\mathrm{ERCC}^{+}$and $\mathrm{BRCA}^{+}$and $\mathrm{ERCC}^{-}(\mathrm{P}=0.032)$.

Short-term outcomes of patients after radiochemotherapy treatment are shown in Table 4 . In primary NPC and cervical lymph nodes, no significant 
differences could be detected in BRCA1 or ERCC1 expression $(\mathrm{P}>0.05)$. Furthermore, in primary NPC and cervical lymph nodes, no significant correlation was detected between BRCA1 and ERCC1 expression ( $\mathrm{P}$ values were 0.218 and 0.338 , respectively).

\section{Long-term outcomes}

The 3-year overall survival (OS), failure-free survival (FFS), locoregional failure-free survival (LRFFS), distant failure-free survival (D-FFS) and median survival time (MST) of BRCA1 and ERCC1 expression groups are shown in Table 5 and Figure 2, Figure 3 and
Figure 4. We found that $\mathrm{ERCC1}^{+}$or $\mathrm{BRCA}^{+}$patients had significantly poorer prognoses than patients with negative expression of ERCC1 and BRCA1. More specifically, patients that were $\mathrm{BRCA} 1^{-}$had a better 3 -year cumulative survival than patients that were $\mathrm{BRCA}^{+}(\mathrm{P}=0.004)$. Moreover, a significant correlation was observed in the negative/positive expression of BRCA1 in 3 year D-FFS $(\mathrm{P}=0.028)$. Unfortunately, no significant differences were found in 3-year LR-FFS between $\mathrm{BRCA}^{-}$and $\mathrm{BRCA}^{+}$ groups $(\mathrm{P}=0.085)$. In $\mathrm{BRCA} 1^{-}$patients, the MST was 34.3 months (95\% CL: 33.9 - 35.3), whereas in BRCA1 ${ }^{+}$ patients MST was 30.8 months (95\% CL: 28.8 - 31.9).
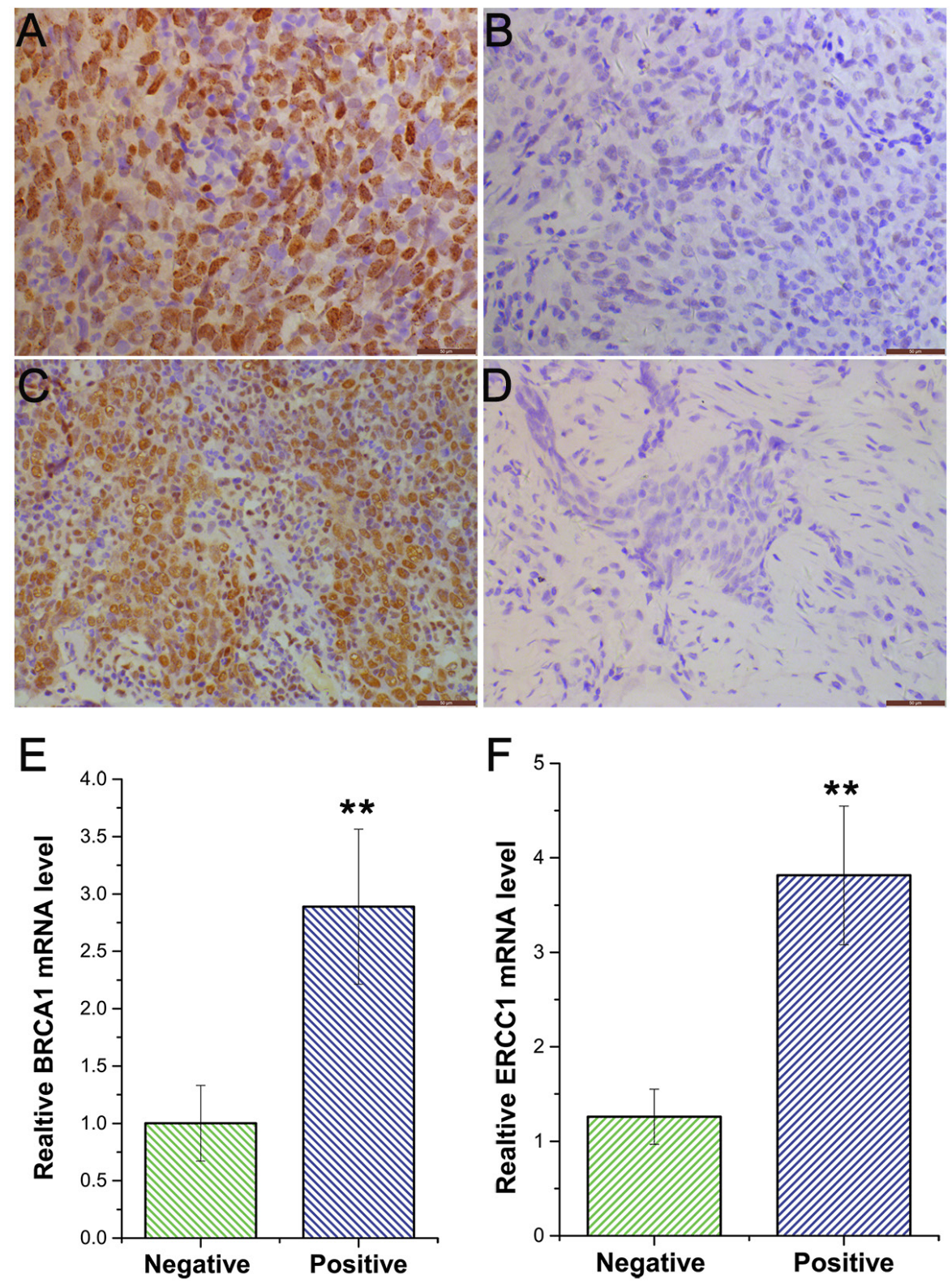

Figure 1: Immunostaining of BRCA1 and ERCC1 protein in nasopharyngeal carcinoma. A. BRCA1 positive expression (X400); B. BRCA1 negative expression (X400); C. ERCC1 positive expression (X400); D. ERCC1 negative expression (X400). E. Quantification of BRCA1 expression by RT-PCR; F. Quantification of ERCC1 expression by RT-PCR. 
Table 1: BRCA1 expression and relationship with clinic pathological factors in nasopharyngeal carcinoma

\begin{tabular}{|c|c|c|c|c|c|c|c|c|}
\hline \multirow[t]{2}{*}{ Characteristics } & \multicolumn{4}{|c|}{ BRCA1 expression } & \multicolumn{4}{|c|}{ ERCC1 expression } \\
\hline & $\mathbf{N}$ & Positive & Negative & P value ${ }^{1}$ & $\mathbf{N}$ & Positive & Negative & P value \\
\hline \multicolumn{9}{|l|}{ SEX } \\
\hline Male & 132 & 86 & 46 & 0.757 & 132 & 94 & 38 & 0.154 \\
\hline Female & 69 & 43 & 26 & & 69 & 42 & 27 & \\
\hline \multicolumn{9}{|l|}{ Age(yr) } \\
\hline$\leq 60$ & 178 & 119 & 59 & 0.037 & 178 & 118 & 60 & 0.344 \\
\hline$>60$ & 23 & 10 & 13 & & 23 & 18 & 5 & \\
\hline \multicolumn{9}{|l|}{$\begin{array}{l}\text { WHO pathology } \\
\text { classification }\end{array}$} \\
\hline I (keratinizing) & 4 & 1 & 3 & 0.069 & 4 & 4 & 0 & $<0.001$ \\
\hline II (nonkeratinizig) & 159 & 99 & 60 & & 159 & 96 & 63 & \\
\hline III(undifferentiated) & 38 & 29 & 9 & & 38 & 36 & 2 & \\
\hline \multicolumn{9}{|l|}{ T stage } \\
\hline $\mathrm{T} 1$ & 10 & 8 & 2 & 0.275 & 10 & 5 & 5 & 0.547 \\
\hline $\mathrm{T} 2$ & 76 & 43 & 33 & & 76 & 50 & 26 & \\
\hline $\mathrm{T} 3$ & 71 & 47 & 24 & & 71 & 49 & 22 & \\
\hline $\mathrm{T} 4$ & 44 & 31 & 13 & & 44 & 32 & 12 & \\
\hline \multicolumn{9}{|l|}{$\begin{array}{l}\text { Lymph node } \\
\text { metastasis }\end{array}$} \\
\hline No & 24 & 15 & 9 & 0.952 & 24 & 18 & 6 & 0.190 \\
\hline N1 & 63 & 40 & 23 & & 63 & 37 & 26 & \\
\hline N2 & 77 & 50 & 27 & & 77 & 57 & 20 & \\
\hline N3 & 37 & 24 & 13 & & 37 & 23 & 14 & \\
\hline \multicolumn{9}{|l|}{$\begin{array}{l}\text { TNM stage AJCC } \\
\text { group (6th ed.) }\end{array}$} \\
\hline III & 123 & 75 & 48 & 0.291 & 123 & 86 & 37 & 0.440 \\
\hline IV & 78 & 54 & 24 & & 78 & 50 & 28 & \\
\hline
\end{tabular}

${ }^{1}$ Statistical analysis was estimated by $\chi 2$ test, and $\mathrm{P}<0.05$ was considered statistically significant; WHO, World Health Organization; AJCC, American Joint Committee on Cancer.

Table 2: The correlation between BRCA1 and ERCC1 expression

\begin{tabular}{lcccc}
\hline & BRCA1 (+) & BRCA1(-) & R & P1 $^{1}$ \\
\hline $\operatorname{ERCC1}(+)$ & 103 & 33 & 0.348 & 0.000 \\
$\operatorname{ERCC1}(-)$ & 26 & 39 & & \\
\hline
\end{tabular}

${ }^{1}$ Statistical analysis was estimated with Spearman correlation analysis, and $\mathrm{P}<0.05$ was considered statistically significant.

Similarly, the 3-year cumulative survival in ERCC1 ${ }^{-}$ patients was higher than in $\mathrm{ERCC} 1^{+}$patients $(\mathrm{P}=0.009)$. In addition, a statistically significant difference was observed in 3-year D-FFS between ERCC1 ${ }^{-}$and ERCC1 ${ }^{+}$patients $(\mathrm{P}=0.036)$. In addition, the 3 -year LR-FFS in
$\mathrm{ERCC1}^{-}$patients was significantly different from that observed in $\mathrm{ERCC1}^{+}$patients $(\mathrm{P}=0.044)$. In ERCC1 ${ }^{-}$ patients, the MST was 34.8 months (95\% CL: 32.7 - 35.8) and in $\mathrm{ERCC}^{+}$patients, MST was 31.6 months (95\% CL: 29.8 - 32.6). 
Table 3: Association of BRCA1 and ERCC1 and the effect of chemotherapy in primary nasopharyngeal carcinoma and cervical lymph node

\begin{tabular}{|c|c|c|c|c|c|c|c|}
\hline Expression & & & Response & & & & \\
\hline In primary & & $\mathbf{N}$ & $\mathbf{C R}+\mathbf{P R}$ & SD+PD & RR (\%) & $X^{2}$ & $\mathbf{P}^{1}$ \\
\hline \multicolumn{8}{|l|}{ BRCA1 } \\
\hline+ & & 129 & 72 & 57 & 55.8 & 6.224 & 0.013 \\
\hline- & & 72 & 53 & 19 & 73.6 & & \\
\hline \multicolumn{8}{|l|}{ ERCC1 } \\
\hline+ & & 136 & 77 & 59 & 56.6 & 7.795 & 0.005 \\
\hline- & & 65 & 50 & 15 & 76.9 & & \\
\hline BRCA1 & ERCC1 & & & & & & \\
\hline+ & + & 103 & 54 & 49 & 52.4 & 12.840 & 0.005 \\
\hline- & - & 39 & 32 & 7 & 82.1 & & \\
\hline+ & - & 26 & 19 & 7 & 73.1 & & \\
\hline - & + & 33 & 23 & 10 & 69.6 & & \\
\hline \multicolumn{8}{|c|}{ In cervical lymph node } \\
\hline \multicolumn{8}{|l|}{ BRCA1 } \\
\hline+ & & 129 & 86 & 43 & 66.6 & 4.387 & 0.036 \\
\hline- & & 72 & 58 & 14 & 80.5 & & \\
\hline \multicolumn{8}{|l|}{ ERCC1 } \\
\hline+ & & 136 & 89 & 47 & 65.4 & 5.496 & 0.019 \\
\hline- & & 65 & 53 & 12 & 81.5 & & \\
\hline BRCA1 & ERCC1 & & & & & & \\
\hline+ & + & 103 & 62 & 41 & 60.1 & 8.831 & 0.032 \\
\hline- & - & 39 & 33 & 6 & 84.6 & & \\
\hline+ & - & 26 & 20 & 6 & 76.9 & & \\
\hline- & + & 33 & 24 & 9 & 72.7 & & \\
\hline
\end{tabular}

${ }^{1}$ Statistical analysis was estimated by $\chi 2$ test, and $\mathrm{P}<0.05$ was considered statistically significant; $\mathrm{CR}$, complete response; $\mathrm{PR}$, partial response; $\mathrm{SD}$, stable disease; $\mathrm{PD}$, progressive disease, $\mathrm{RR}$, response rate.

The correlation between BRCA1 and ERCC1 expression and 3-year OS, FFS, LR-FFS, D-FFS and MST are summarized in Table 5, Figure 2, Figure 3 and Figure 4. We found that patients with BRCA1 ${ }^{-}$and $\mathrm{ERCC1}^{-}$expression had a significantly better prognosis than patients that showed $\mathrm{BRCA}^{+}$and $\mathrm{ERCC1}^{+}$ expression, $\mathrm{BRCA}^{-}$and $\mathrm{ERCC} 1^{+}$expression, or $\mathrm{BRCA}^{+}$ and $\mathrm{ERCC} 1^{-}$expression. The 3-year cumulative survival was significantly higher $\mathrm{ERCC} 1^{-} / \mathrm{BRCA}^{-}$patients than in $\mathrm{BRCA1}^{+} / \mathrm{ERCC}^{+}{ }^{+}$patients, $\mathrm{BRCA} 1^{+} / \mathrm{ERCC1}^{-}$patients and $\mathrm{BRCA1} 1^{-} / \mathrm{ERCC1}^{+}$patients $(\mathrm{P}=0.001)$. The 3 -year D-FFS was also significantly different in patients with $\mathrm{BRCA}^{-}$and $\mathrm{ERCC} 1^{-}, \mathrm{BRCA}^{+}{ }^{+}$and $\mathrm{ERCCl}^{+}, \mathrm{BRCA}^{+}$ and $\mathrm{ERCC1}^{-}$and $\mathrm{BRCA}^{-}$and $\mathrm{ERCC1}^{+}(\mathrm{P}=0.004)$. However, no significant differences were observed between BRCA1 and ERCC1 expression in 3-year LRFFS $(\mathrm{P}>0.05)$. The MST was 36 months for $\mathrm{BRCA} 1^{-}$and ERCC1- patients (95\% CL: 36.0 - 36.0), 30.5 months for $\mathrm{BRCA}^{+}{ }^{+}$and $\mathrm{ERCC1}^{+}$patients (95\% CL: 28.5 - 31.7), 34.6 months for $\mathrm{BRCA}^{+}$and $\mathrm{ERCC1} 1^{-}$patients $(95 \% \mathrm{CL}$ : $32.4-35.1)$ and 32.2 months for $\mathrm{BRCA}^{-}$and $\mathrm{ERCC} 1^{+}$ patients (95\% CL: 29.5 - 34.9).

In this study, we performed Cox regression for univariate and multivariate analyses (Table 6). Univariate analyses shown that BRCA1 expression, ERCC1 expression, and TNM stage were related to overall survival $(\mathrm{P}=0.042,0.014$ and 0.024 , respectively). In addition, we found that the correlation between BRCA1 and ERCC1 expression was also related to overall survival $(\mathrm{P}<0.05$ in all cases). Multivariate analyses further indicated 
Table 4: Association of BRCA1 and ERCC1 and the effect of radiochemotherapy in primary nasopharyngeal carcinoma and cervical lymph node

\begin{tabular}{|c|c|c|c|c|c|c|c|}
\hline \multirow{2}{*}{$\begin{array}{l}\text { Expression } \\
\text { In primary }\end{array}$} & & \multicolumn{3}{|c|}{ Response } & \multirow[b]{2}{*}{$\operatorname{RR}(\%)$} & \multirow[b]{2}{*}{$\mathrm{X}^{2}$} & \multirow[b]{2}{*}{$\mathbf{P}^{1}$} \\
\hline & & $\mathbf{N}$ & CR & PR & & & \\
\hline \multicolumn{8}{|l|}{ BRCA1 } \\
\hline+ & & 129 & 106 & 22 & 82.1 & 2.071 & 0.209 \\
\hline- & & 72 & 65 & 7 & 90.2 & & \\
\hline \multicolumn{8}{|l|}{ ERCC1 } \\
\hline+ & & 136 & 113 & 23 & 83.1 & 0.715 & 0.532 \\
\hline- & & 65 & 57 & 8 & 87.6 & & \\
\hline BRCA1 & ERCC1 & & & & & & \\
\hline+ & + & 103 & 84 & 19 & 81.5 & 4.243 & 0.218 \\
\hline- & - & 39 & 37 & 2 & 94.8 & & \\
\hline+ & - & 26 & 23 & 3 & 88.4 & & \\
\hline - & + & 33 & 28 & 4 & 84.8 & & \\
\hline \multicolumn{8}{|c|}{ In cervical lymph node } \\
\hline \multicolumn{8}{|l|}{ BRCA1 } \\
\hline+ & & 129 & 118 & 11 & 91.4 & 1.356 & 0.387 \\
\hline- & & 72 & 69 & 3 & 95 & & \\
\hline \multicolumn{8}{|l|}{ ERCC1 } \\
\hline+ & & 136 & 123 & 13 & 90.4 & 3.437 & 0.108 \\
\hline- & & 65 & 64 & 1 & 98.4 & & \\
\hline BRCA1 & ERCC1 & & & & & & \\
\hline+ & + & 103 & 91 & 12 & 88 & 3.370 & 0.338 \\
\hline- & - & 39 & 38 & 1 & 97 & & \\
\hline+ & - & 26 & 24 & 2 & 92 & & \\
\hline - & + & 33 & 31 & 2 & 93 & & \\
\hline
\end{tabular}

${ }^{1}$ Statistical analysis was estimated by $\chi 2$ test, and $\mathrm{P}<0.05$ was considered statistically significant; $\mathrm{CR}$, complete response; $\mathrm{PR}$, partial response; $\mathrm{RR}$, response rate.

that ERCC1 expression, TNM stage and the correlation between ERCC1 and BRCA1 expression were prognostic factors for $\mathrm{OS}(\mathrm{P}<0.05$ in all cases $)$.

\section{DISCUSSION}

NPC is a malignant tumor, with a approximate incidence of 20/100,000 in China [12]. Because over half of the NPC patients fall in the International Union Against Cancer Stage III or IV [13], defining the optimal treatment for patients with NPC is of utmost importance. Induction chemotherapy combined with radiotherapy is one of the most significant strategies for patients with advanced NPC [13-17]. Platinum-based induction chemotherapy response rate and OS differ between NPC patients, which may be due to the fact that patients may have developed drug resistance and toxicity. Therefore, it is necessary to decide that the induction chemotherapy which based on platinum could be good for what kind of patients. Biomarkers that could help diagnose NPCs may assist in identifying the most appropriate forms of chemotherapy and radiochemotherapy for NPCs.

In our work, we investigated whether BRCA1 and ERCC1 could act as biomarkers. In addition, we presented separate analyses for ORR of primary tumor and neck nodes based on BRCA1 and ERCC1 expression in primary NPC in order to assess whether or not the different treatments affect the primary tumor and the metastatic sites. Currently, treatment decisions are usually based on immunohistochemistry date of the primary tumor. Some 
Table 5: The correlation between BRCA1 and ERCC1 expressions in long-term outcomes

\begin{tabular}{|c|c|c|c|c|c|c|c|c|c|c|}
\hline \multicolumn{2}{|c|}{ Expression } & $\begin{array}{c}\text { 3-year OS } \\
(\%)\end{array}$ & $\begin{array}{c}\mathbf{P}^{1} \\
\text { value }\end{array}$ & $\begin{array}{c}\text { 3-year FFS } \\
(\%)\end{array}$ & $\begin{array}{c}P^{1} \\
\text { value }\end{array}$ & $\begin{array}{c}\text { 3-year LR- } \\
\text { FFS (\%) }\end{array}$ & $\begin{array}{c}\mathbf{P}^{1} \\
\text { value }\end{array}$ & $\begin{array}{c}\text { 3-year D-FFS } \\
(\%)\end{array}$ & $\begin{array}{c}\mathbf{P}^{1} \\
\text { value }\end{array}$ & $\begin{array}{c}\text { MST } \\
\text { (Months) }\end{array}$ \\
\hline \multicolumn{11}{|l|}{ BRCA1 } \\
\hline+ & & $\begin{array}{c}72.8 \\
(94 / 129)\end{array}$ & 0.004 & $\begin{array}{c}73.6 \\
(95 / 129)\end{array}$ & 0.048 & $\begin{array}{c}79.8 \\
(102 / 129)\end{array}$ & 0.085 & $\begin{array}{c}82.2 \\
(106 / 129)\end{array}$ & 0.028 & $\begin{array}{c}30.8 \\
(28.8-31.9)\end{array}$ \\
\hline- & & $\begin{array}{c}81.9 \\
(59 / 72)\end{array}$ & & $\begin{array}{c}83.3 \\
(60 / 72)\end{array}$ & & $\begin{array}{c}88.9 \\
(64 / 72)\end{array}$ & & $\begin{array}{c}88.9 \\
(64 / 72)\end{array}$ & & $\begin{array}{c}34.3 \\
(33.9-35.3)\end{array}$ \\
\hline \multicolumn{11}{|l|}{ ERCC1 } \\
\hline+ & & $\begin{array}{c}77.8 \\
(98 / 136)\end{array}$ & 0.009 & $\begin{array}{c}72.7 \\
(99 / 136)\end{array}$ & 0.036 & $\begin{array}{c}77.9 \\
(106 / 136)\end{array}$ & 0.044 & $\begin{array}{c}82.4 \\
(112 / 136)\end{array}$ & 0.036 & $\begin{array}{c}31.6 \\
(29.8-32.6)\end{array}$ \\
\hline- & & $\begin{array}{c}84.6 \\
(55 / 65)\end{array}$ & & $\begin{array}{c}87.6 \\
(57 / 65)\end{array}$ & & $\begin{array}{c}92.3 \\
(60 / 65)\end{array}$ & & $\begin{array}{c}89.2 \\
(58 / 65)\end{array}$ & & $\begin{array}{c}34.8 \\
(32.7-35.8)\end{array}$ \\
\hline \multicolumn{11}{|c|}{ BRCA1 ERCC1 } \\
\hline+ & + & $\begin{array}{c}75.7 \\
(78 / 103)\end{array}$ & 0.001 & $\begin{array}{c}62.1 \\
(64 / 103)\end{array}$ & 0.002 & $\begin{array}{c}76.6 \\
(79 / 103)\end{array}$ & 0.163 & $\begin{array}{c}79.6 \\
(82 / 103)\end{array}$ & 0.004 & $\begin{array}{c}30.5 \\
(28.5-31.7)\end{array}$ \\
\hline- & - & $\begin{array}{c}100 \\
(39 / 39)\end{array}$ & & $\begin{array}{c}100 \\
(39 / 39)\end{array}$ & & $\begin{array}{c}100 \\
(39 / 39)\end{array}$ & & $\begin{array}{c}100 \\
(39 / 39)\end{array}$ & & $\begin{array}{c}36 \\
(36-36)\end{array}$ \\
\hline+ & - & $\begin{array}{c}81.0 \\
(21 / 26)\end{array}$ & & $\begin{array}{c}84.6 \\
(22 / 26)\end{array}$ & & $\begin{array}{c}92.3 \\
(24 / 26)\end{array}$ & & $\begin{array}{c}84.6 \\
(22 / 26)\end{array}$ & & $\begin{array}{c}34.6 \\
(32.4-35.1)\end{array}$ \\
\hline - & + & $\begin{array}{c}78.7 \\
(26 / 33)\end{array}$ & & $\begin{array}{c}72.7 \\
(24 / 33)\end{array}$ & & $\begin{array}{c}81.8 \\
(27 / 33)\end{array}$ & & $\begin{array}{c}90.9 \\
(30 / 33)\end{array}$ & & $\begin{array}{c}32.2 \\
(29.5-34.9)\end{array}$ \\
\hline
\end{tabular}

1: Statistical analysis was estimated with $\log$-rank, and $\mathrm{P}<0.05$ was considered statistically significant; OS: overall survival; FFS: failure-free survival; LR-FFS: locoregional failure-free survival; D-FFS: distant failure-free survival.

clinical researches provided the suggestions that the status of some bio markers may alter between the primary tumor and the corresponding distant metastatic sites, including epidermal growth factor receptor (EGFR), multidrug resistance (MDR), and HER-2 [18-20]. This might be the reason that the genes in the tumor are deformed, for instance, the deficiency of chromosomal or gene silencing, and in some cases, the loss of expression in metastatic cells [21]. This biological phenomenon would explain the resistance of tumor to specific bio markers in a way, so called targeted antibody therapy if it is confirmed, while most have been still investigated somehow.
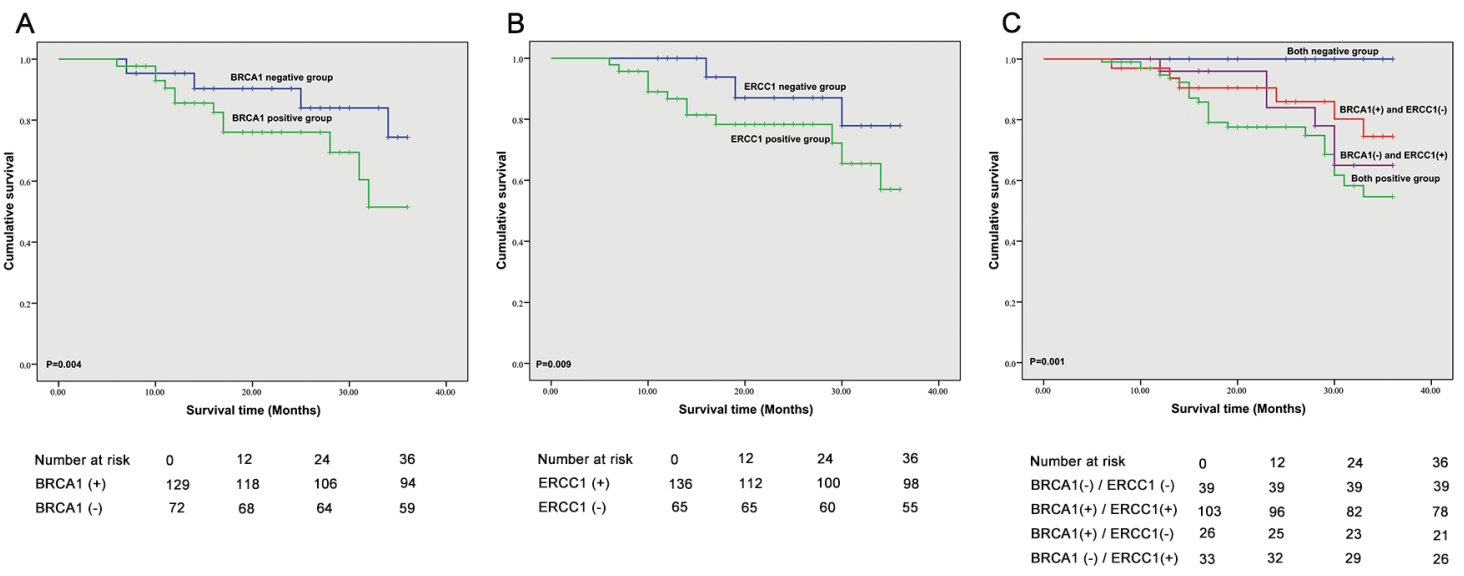

Figure 2: Correlation of BRCA1 and ERCC1 expression and overall survival. A. Correlation between BRCA1 expression and overall survival (OS); B. Correlation between ERCC1 expression and OS; C. Correlation between BRCA1 and ERCC1 expression and OS. 
We found that BRCA1 and ERCC1 positiveexpression are associated with poor prognosis in NPCs. We found that ERCC1 expression correlates with pathology classification, and that $\mathrm{ERCC1}^{-}$patients benefit more from platinum-based chemotherapy than $\mathrm{ERCC}^{+}$. This suggests that there is a inversely relation between ERCC1 expression and the objective response to platinumbased induction chemotherapy. This may be due to the fact that platinum-based chemotherapy enters the cells and binds to DNA, which then forms a platinum-DNA adduct, and holds back cellular proliferation and transcription through nucleotide excision repair (NER) pathway, and may lead to tumor cell death. ERCC1 accounts for most platinum-DNA adduct repairs. Furthermore, patients who received radiochemotherapy had excellent efficacy (CR were about $90 \%$ in all cases) in primary NPC and cervical lymph nodes, which makes it challenging to predict the therapeutic effect between $\mathrm{ERCC} 1{ }^{-}$and $\mathrm{ERCC} 1^{+}$patients.

The single factor analysis (Kaplan-Meier method) showed ERCC1 expression was associated with OS, FFS, LR-FFS, and D-FFS. The Cox regression analysis demonstrated that ERCC1 expression was a significant factor for OS. These findings are consistent with previous reports [22-26], and confirm that ERCC1 may be a predictor for the prognosis of NPC. Hui and Koh [27, 28] did not show clinical impact of ERCC1 in NPC patients treated with platinumbased induction. The abnormal situation was caused possibly because of the two different treatment methods that were used in the two researches. In Hui and Koh's study, NPCs undergo concurrent-adjuvant chemoradiotherapy or radiotherapy alone. However, the NPCs in our work received induction chemotherapy + concurrent-adjuvant chemoradiotherapy.
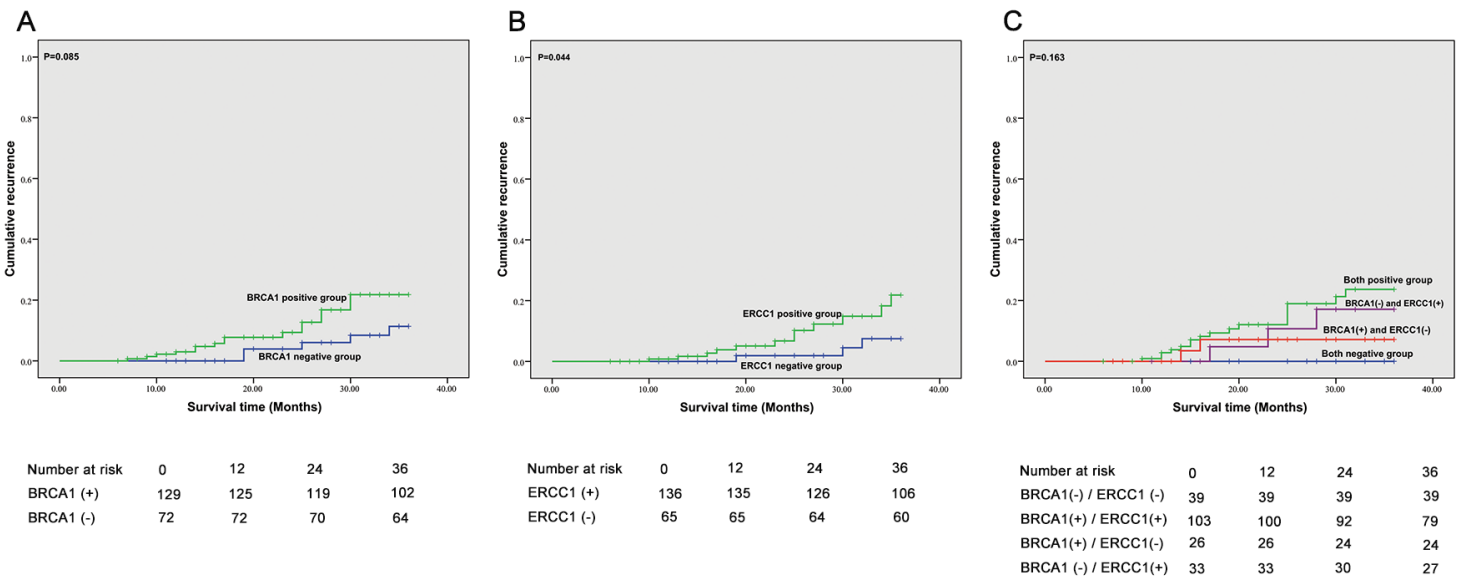

Figure 3: Correlation between expression of BRCA1 and ERCC1 recurrence. A. Correlation between BRCA1 expression and recurrence; B. Correlation between ERCC1 expression and recurrence; C. Correlation between BRCA1 and ERCC1 expression and recurrence.

A

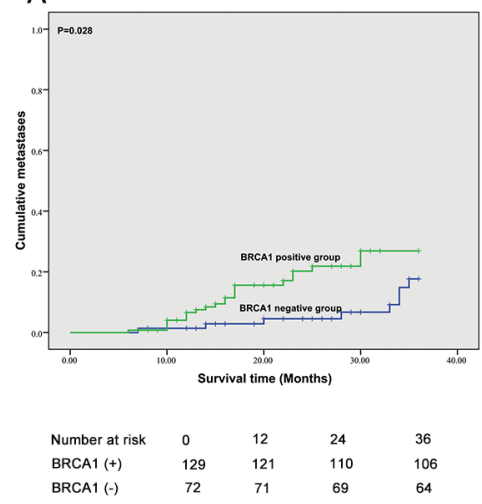

B

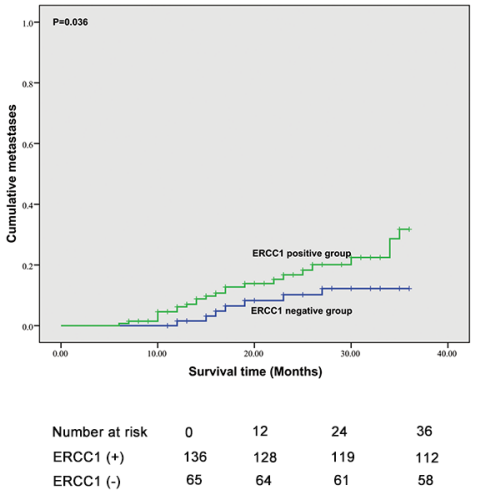

C

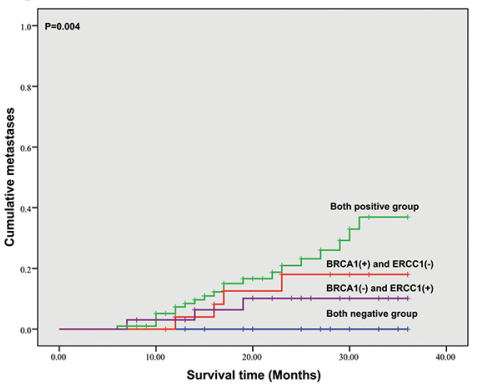

$\begin{array}{lllll}\text { Number at risk } & 0 & 12 & 24 & 36 \\ \text { BRCA1(-)/ ERCC1 }(-) & 39 & 39 & 39 & 39 \\ \text { BRCA1(+) / ERCC1(+) } & 103 & 96 & 88 & 82 \\ \text { BRCA1(+) / ERCC1(-) } & 26 & 25 & 22 & 22 \\ \text { BRCA1 (-) / } \text { ERCC } 1(+)^{+} & 33 & 32 & 30 & 30\end{array}$

Figure 4: Correlation between BRCA1 and ERCC1 expression and metastases. A. Correlation between BRCA1 expression and metastases; B. Correlation between ERCC1 expression and metastases; C. Correlation between BRCA1 and ERCC1 expression and metastases. 
Table 6: Univariate and multivariate analyses of survival (Cox regression)

\begin{tabular}{|c|c|c|}
\hline \multirow[t]{2}{*}{ Variables } & \multicolumn{2}{|c|}{ Survival } \\
\hline & HR $(95 \%$ CI) & P value \\
\hline \multicolumn{3}{|l|}{ Univariate analysis } \\
\hline Sex & $0.614(0.223-1.692)$ & 0.346 \\
\hline \multicolumn{3}{|l|}{ Male/female } \\
\hline Age (yr) & $1.395(0.408-4.769)$ & 0.595 \\
\hline \multicolumn{3}{|l|}{$\leq 60 />60$} \\
\hline WHO pathology classification & $0.382(0.110-1.330)$ & 0.131 \\
\hline \multicolumn{3}{|l|}{$\begin{array}{l}\text { Keratinizing } \\
\text { Nonkeratinizig } \\
\text { undifferentiated }\end{array}$} \\
\hline T stage & $2.823(0.943-8.447)$ & 0.064 \\
\hline \multicolumn{3}{|l|}{ T1-T2/T3-T4 } \\
\hline Lymph node metastasis & $0.502(0.168-1.505)$ & 0.219 \\
\hline \multicolumn{3}{|l|}{$\mathrm{N} 0 / \mathrm{N} 1-3$} \\
\hline TNM stage & $2.877(1.147-7.213)$ & 0.024 \\
\hline \multicolumn{3}{|l|}{ III/IV } \\
\hline BRCA1 expression & $3.141(1.041-9.472)$ & 0.042 \\
\hline \multicolumn{3}{|l|}{ Negative/positive } \\
\hline ERCC1 expression & $6.327(1.457-27.483)$ & 0.014 \\
\hline \multicolumn{3}{|l|}{ Negative/positive } \\
\hline \multicolumn{3}{|c|}{ Correlation between BRCA1 and ERCC1 } \\
\hline BRCA1 $(-)$ and ERCC1 $(-)$ & Reference group & \\
\hline BRCA1 $(+)$ and ERCC1 $(-)$ & $4.126(1.268-13.428)$ & 0.019 \\
\hline BRCA1 $(-)$ and ERCC1 $(+)$ & $4.297(1.363-13.545)$ & 0.013 \\
\hline BRCA1 $(+)$ and $\operatorname{ERCC} 1(-)$ & $4.410(1.543-12.604)$ & 0.006 \\
\hline \multicolumn{3}{|l|}{ Multivariate analysis } \\
\hline TNM stage & $2.923(1.155-7.393)$ & 0.024 \\
\hline \multicolumn{3}{|l|}{ III/IV } \\
\hline BRCA1 expression & $1.743(0.557-5.456)$ & 0.340 \\
\hline \multicolumn{3}{|l|}{ Negative/positive } \\
\hline ERCC1 expression & $5.582(1.233-25.274)$ & 0.026 \\
\hline \multicolumn{3}{|l|}{ Negative/positive } \\
\hline \multicolumn{3}{|c|}{ Correlation between BRCA1 and ERCC1 } \\
\hline BRCA1 (-) and ERCC1 (-) & Reference group & \\
\hline BRCA1 $(+)$ and ERCC1 $(-)$ & $3.582(1.098-11.6 .85)$ & 0.034 \\
\hline BRCA1 $(-)$ and ERCC1 $(+)$ & $4.786(1.516-15.107)$ & 0.008 \\
\hline BRCA1 $(+)$ and $\operatorname{ERCC} 1(+)$ & $5.157(1.798-14.792)$ & 0.002 \\
\hline
\end{tabular}

HR: Hazard ratio; CI: Confidence interval. 
We found out that BRCA1 expression correlates with age and that expression is negative correlated to the objective response of platinum-based induction chemotherapy similar to that of ERCC1. This could be due to the fact that BRCA1 is also a key role in the NER pathway. The result found in NPC corresponded to gastric cancer and bladder cancer [29, 30]. After concurrent chemoradiotherapy, no significant differences were found in primary NPC and cervical lymph node between $\mathrm{BRCA1}^{-}$and $\mathrm{BRCA1}^{+}$patients (CR about $90 \%$ in all cases). In a subsequent study, the Kaplan-Meier method showed that BRCA1 expression was associated with OS, FFS and D-FFS, but not LR-FFS. We inferred that BRCA1 expression has an impact on the chemotherapy response on micrometastatic spread when the NPC was diagnosed at the very beginning [23], therefore NPC patients had different OS and D-FFS without different LR-FFS. The univariate analysis confirmed the association between BRCA1 expression and OS. Multivariate analysis, however, did not support this association. This may be due to the fact that the number of patients in this work was relatively small. If the number of patients were increased, the association between BRCA1 expression and OS would possibly reach significance.

In this study, we first describe the negative correlation between BRCA1 and ERCC1 expression $(\mathrm{R}=0.348, \mathrm{P}<0.01)$. We found that patients with negative expression of BRCA1 and ERCC1 have a better therapeutic outcome after chemotherapy and concurrent radiochemotherapy than patients with both positive expression of BRCA1 and ERCC1, BRCA1 $1^{+}$and $\mathrm{ERCC}^{-}$, and $\mathrm{BRCA1}^{-}$and $\mathrm{ERCC}^{+}$. This may be due to the synergistic effect between of BRCA1 and ERCC1. Kaplan-Meier survival analysis demonstrated that patients with negative expression of both BRCA1 and ERCC1 had a better 3-year OS, FFS and D-FFS ( $\mathrm{P}<0.05$ in all cases). Univariate and multivariate analysis also demonstrated a statistically significant difference between BRCA1 and ERCC1 expression and OS, indicating a close correlation between $\mathrm{BRCA}^{-}$and $\mathrm{ERCC}^{-}$and OS. These factors support our hypothesis that $\mathrm{BRCA}^{-}$or $\mathrm{ERCC1}^{-}$patients benefitted more from chemotherapy and had a better prognosis.

Although the results are promising, there are few limitations to our study. First, this work lacks a validation cohort, hence future studies need to confirm our results. Second, the study groups used were relatively small, with a limited number of patients, and rather short-term following up. Therefore, large sample multicenter studies will be required to validate our data set.

\section{MATERIALS AND METHODS}

\section{Subjects}

A total of 201 patients were enrolled at the Affiliated Hospital of SOUTHWEST Medical University between February 2010 and February 2012. Follow up was until until February 2015. Inclusion criteria included the following: biopsy proven stage III to IV NPC according to the American Joint Committee on Cancer (AJCC) Cancer Staging Manual (sixth edition) [31]; no radiotherapy or chemotherapy before biopsy; no major organ dysfunction; no history of other malignancies; age $>18$ years. Patients with a prior history of malignancy, pregnancy, contraindications for chemotherapy, or a history of chemotherapy, radiotherapy, or surgery were excluded from the study. All samples were collected by biopsy via nasopharyngoscopy. Informed consent was obtained from all patients before conducting the study.

\section{Study design}

All patients were analyzed using a spiral chest CT scan, chest $\mathrm{X}$ ray, bone scan and abdominal ultrasonogram. In addition, patients received enhanced MRI scanning in the nasopharynx and neck area in order to delineate their primary NPC and neck lymph node metastases for appraisal before treatment. Blood routine, electrocardiogram, biochemical, and plasma electrolytes were determined to eliminate chemotherapeutic contraindication. Eligible patients first received intravenous platinum-based chemotherapy, when finishing their chemotherapy, patients received enhanced MRI scanning in the nasopharynx and neck area to estimate the curative effect. Then they treated with concurrent chemoradiotherapy, when finishing their chemoradiotherapy, patients once again to received enhanced MRI scanning in the nasopharynx and neck area to estimate the curative effect (Figure 1). The treatment regimens included $80 \mathrm{mg} / \mathrm{m}^{2}$ cisplatin on day 1 and $5-\mathrm{FU}$ $1000 \mathrm{mg} / \mathrm{m}^{2}$ on day 2, 3 and 4. Chemotherapy cycles were administrated every 4 weeks for a maximum of 2 cycles. After finishing their chemotherapy, patients received concurrent chemoradiotherapy. This treatment regimen included radiation dose with 66-70Gy $(2.2 \mathrm{~Gy}$ per treatment) for primary NPC and nodal metastasis, radiation dose with 44-64Gy (1.6-2.0Gy per treatment) for bilateral neck, and $40 \mathrm{mg} / \mathrm{m}^{2}$ cisplatin per week.

\section{Gene expression analysis by real-time quantitative PCR}

Specimens were pulverized by pulp refiner under Trizol reagent (Invitrogen). RNA was extracted with Trizol reagent and dissolved in DEPC water. Total RNA were reverse transcribed with RevertAid ${ }^{\mathrm{TM}}$ First Strand cDNA Synthesis Kit (Fermentas) for generation of cDNA. Gene expression for ERCC1, BRCA1, and GAPDH (internal reference gene) were performed using RT-PCR. The sequences of the primers used were as follows: BRCA1 Forward 5'-GTCCAAAGCGAGCAAGAG-3', Reverse 5'-CTGTGCCAAGGGTGAATG-3; ERCC1 Forward 5'-GATGAGGTCCCTCCTGGAGTGG-3', Reverse 
5'-AGATGGCATATTCGGCGTAGGTC-3; GAPHD (internal reference gene) Forward 5'-CATGAGAAG TATGACAACAGCCT-3', Reverse 5'-AGTCCTTCC ACGATACCAAAGT-3; GAPHD was used as an endogenous control and data obtained were represented as 2-DDCT [32]. The amplification parameters consisted of 40 cycles at $94{ }^{\circ} \mathrm{C}$ for $40 \mathrm{~s}$, annealing at different temperature for different gene for $40 \mathrm{~s}, 72^{\circ} \mathrm{C}$ for $50 \mathrm{~s}$. The threshold cycle (CT) data was determinate using default threshold settings. The CT is defined as the fractional cycle number at which the fluorescence passes the fixed threshold.

\section{Immunohistochemistry}

ERCC1 and BRCA1 expression were examined immunohistochemically using paraffin-embedded tissues. In brief, 3- $\mu \mathrm{m}$-thick tissue sections were heated in 6.5 $\mathrm{mmol} / \mathrm{L}$ citrate buffer $(\mathrm{pH} 6.0)$ at $100^{\circ} \mathrm{C}$ for $28 \mathrm{~min}$, and incubated with antibodies directed against ERCC1 or BRCA1 (1:200 dilution). Immunostaining was performed using the DAKO En-Vision System (Dako Diagnostics, Zug, Switzerland). In the negative control group, the primary antibody was replaced by PBS. Expression was scored by two independent experienced pathologists. Each sample was graded according to intensity and extent of staining. The intensity of staining was scored as 0 (no staining), 1 (weak staining), and 2 (strong staining). The extent of staining was based on the percentage of positive tumor cells: 0 (no staining), 1 (1-25\%), 2 (26-50\%), 3 $(51-75 \%)$, and $4(76-100 \%)$. These two scores were added together for a final score. A case was considered negative if the final score was 0 or $1(-)$ or 2 or $3( \pm)$, and positive if the score was 4 or $5(+)$ or 6 or $7(++)$. In the majority of cases, the two examiners provided consistent results. Any inconsistencies were resolved by discussion to achieve a consensus score.

\section{Clinical endpoints and statistical analysis}

We followed reporting recommendations for tumor marker prognostic studies (REMARK) guidelines in our study. Complete remission and partial remission were defined as responsive, stable disease and progressive disease was defined as non-responsive. FFS was defined as the time from the start of chemotherapy or concurrent radiochemotherapy to tumor recurrence, metastasis or dying of the patient, whereas OS was defined as the time from the start of chemotherapy or concurrent radiochemotherapy to dying of the patient or last follow-up.

ERCC1 and BRCA1 expression as well as clinical variables of chemotherapy were evaluated using the $\mathrm{X}^{2}$-test. The correlation between BRCA1 and ERCC1 expression was evaluated using Spearman correlation analysis. The cumulative recurrence, cumulative metastasis and survival probability were estimated using
Kaplan-Meier analysis and differences were calculated by log-rank test. Prognostic factors for survival were determined using Cox regression analysis. All $\mathrm{P}$ values were two-sided; $\mathrm{P}<0.05$ was considered significant. Statistical analyses were performed using SPSS 17.0 software.

\section{CONFLICTS OF INTEREST}

The authors declare no conflicts of interest.

\section{FUNDING}

This work was financially supported by the Union Project of Luzhou City and Southwest Medical University (14JC0144, 2013LZLY-J40).

\section{REFERENCES}

1. Kang M, Liu WQ, Qin YT, Wei ZX, Wang RS. Longterm efficacy of microwave hyperthermia combined with chemoradiotherapy in treatment of nasopharyngeal carcinoma with cervical lymph node metastases. Asian Pacific Journal of Cancer Prevention. 2013; 14:7395-7400.

2. Chang ET, Adami HO. The enigmatic epidemiology of nasopharyngeal carcinoma. Cancer Epidemiology Biomarkers \& Prevention. 2006; 15:1765.

3. Ali H, Al-Sarraf M. Chemotherapy in advanced nasopharyngeal cancer. Oncology. 2000; 14:1223-1230.

4. Lee AW, Poon YF, Foo W, Law SC, Cheung FK, Chan DK, Tung SY, Thaw M, Ho JH. Retrospective analysis of 5037 patients with nasopharyngeal carcinoma treated during 1976-1985: overall survival and patterns of failure. International journal of radiation oncology, biology, physics. 1992; 23:261-270.

5. Xiao WW, Huang SM, Han F, Wu SX, Lu LX, Lin CG, Deng XW, Lu TX, Cui NJ, Zhao C. Local control, survival, and late toxicities of locally advanced nasopharyngeal carcinoma treated by simultaneous modulated accelerated radiotherapy combined with cisplatin concurrent chemotherapy: long-term results of a phase 2 study. Cancer. 2011; 117:1874-1883.

6. Bensouda Y, Kaikani W, Ahbeddou N, Rahhali R, Jabri M, Mrabti H, Boussen H, Errihani H. Treatment for metastatic nasopharyngeal carcinoma. European Annals of Otorhinolaryngology Head \& Neck Diseases. 2011; 128:79.

7. Chen C, Wang FH, Wang ZQ, An X, Luo HY, Zhang L, Chen YC, Xu RH, Li YH. Salvage gemcitabine-vinorelbine chemotherapy in patients with metastatic nasopharyngeal carcinoma pretreated with platinum-based chemotherapy. Oral Oncology. 2012; 48:1146-1151.

8. Martin LP, Hamilton TC, Schilder RJ. Platinum resistance: the role of DNA repair pathways. Clinical Cancer Research. 2008; 14:1291. 
9. Wang L, Wei J, Qian X, Yin H, Zhao Y, Yu L, Wang T, Liu B. ERCC1, BRCA1 mRNA expression levels in metastatic malignant effusions is associated with chemosensitivity to cisplatin and/or docetaxel. BMC Cancer. 2008; 8:1-7.

10. Husain A, He G, Venkatraman ES, Spriggs DR. BRCA1 Up-Regulation Is Associated with Repair-mediated Resistance to cis-Diamminedichloroplatinum(II). Cancer Research. 1998; 58:1120-1123.

11. Gazdar AF. DNA repair, survival in lung cancer--the two faces of Janus. New England Journal of Medicine. 2007; 356:771-773.

12. Xu ZJ, Zheng RS, Zhang SW, Zou XN, Chen WQ. Nasopharyngeal carcinoma incidence and mortality in China in 2009. Chin J Cancer. 2013; 32:453-460.

13. Chan SH, Cheung FMF, Ng WT, Choi CW, Cheung KN, Yiu KH, Lee AWM. Can the Analysis of ERCC1 Expression Contribute to Individualized Therapy in Nasopharyngeal Carcinoma? International Journal of Radiation Oncology Biology Physics. 2011; 79:1414-1420.

14. Chua DTT, Jun M, Sham JST, Hai-Qiang M, Choy DTK, Ming-Huang H, Tai-Xiang L, Hua-Qing M. Long-term survival after cisplatin-based induction chemotherapy and radiotherapy for nasopharyngeal carcinoma: a pooled data analysis of two phase III trials. Journal of Clinical. 2005; 23:1118-1124.

15. Lee AWM, Lau KY, Hung WM, Ng WT, Lee MCH, Choi CW, Chan CCC, Tung R, Cheng PTC, Yau TK. Potential improvement of tumor control probability by induction chemotherapy for advanced nasopharyngeal carcinoma. Radiotherapy and Oncology. 2008; 87:204-210.

16. Yau TK, Lee AWM, Wong DHM, Yeung RMW, Chan EWK, Ng WT, Tong M, Soong IS. Induction chemotherapy with cisplatin and gemcitabine followed by accelerated radiotherapy and concurrent cisplatin in patients with stage IV(A-B) nasopharyngeal carcinoma. Head \& Neck. 2006; 28:880-887.

17. Shueng PW, Shen BJ, Wu LJ, Liao LJ, Hsiao CH, Lin YC, Cheng PW, Lo WC, Jen YM, Hsieh CH. Concurrent imageguided intensity modulated radiotherapy and chemotherapy following neoadjuvant chemotherapy for locally advanced nasopharyngeal carcinoma. Radiation Oncology. 2011; 6:1-8.

18. Becker TE, Ellsworth RE, Deyarmin B, Patney HL, Jordan RM, Hooke JA, Shriver CD, Ellsworth DL. The genomic heritage of lymph node metastases: Implications for clinical management of patients with breast cancer. Annals of Surgical Oncology. 2008; 15:1056-1063.

19. Min AK, Lee HJ, Yang HK, Bang YJ, Kim WH. Heterogeneous amplification of ERBB2 in primary lesions is responsible for the discordant ERBB2 status of primary and metastatic lesions in gastric carcinoma. Histopathology. 2011; 59:822-831.

20. Scartozzi M, Bearzi I, Berardi R, Mandolesi A, Fabris G, Cascinu S. Epidermal growth factor receptor (EGFR) status in primary colorectal tumors does not correlate with EGFR expression in related metastatic sites: implications for treatment with EGFR-targeted monoclonal antibodies. Journal of Clinical Oncology. 2004; 22:4772-4778.

21. Italiano A, Saintpaul MC, Carolibosc FX, François E, Bourgeon A, Benchimol D, Gugenheim J, Michiels JF. Epidermal growth factor receptor (EGFR) status in primary colorectal tumors correlates with EGFR expression in related metastatic sites: biological and clinical implications. Annals of Oncology. 2005; 16:1503-1507.

22. Lee HW, Hwang YH, Han JH, Choi JH, Kang SY, Jeong SH, Ann MS, Oh YT, Kim JH, Kim CH. High expression of excision repair cross-complementation group1 protein predicts poor outcome in patients with nasopharyngeal cancer. Oral Oncology. 2010; 46:209-213.

23. Huang PY, Li Y, Mai HQ, Luo RZ, Cai YC, Zhang L. Expression of ERCC1 predicts clinical outcome in locoregionally advanced nasopharyngeal carcinoma treated with cisplatin-based induction chemotherapy. Oral Oncology. 2012; 48:964-968.

24. Sun JM, Ahn MJ, Min JP, Lee HY, Jin SA, Lee S, Kang G, Han J, Son YI, Baek CH. Expression of Excision Repair Cross-Complementation Group 1 as Predictive Marker for Nasopharyngeal Cancer Treated With Concurrent Chemoradiotherapy. International Journal of Radiation Oncology Biology Physics. 2011; 80:655-660.

25. Pei-Yu H, Yan L, Hai-Qiang M, Rong-Zhen L, Yu-Chen C, Li Z. Expression of ERCC1 predicts clinical outcome in locoregionally advanced nasopharyngeal carcinoma treated with cisplatin-based induction chemotherapy. Oral Oncology. 2012; 48:964-968.

26. Handra-Luca A, Hernandez J, Mountzios G, Taranchon E, Lacau-St-Guily J, Soria JC, Fouret P. Excision repair cross complementation group 1 immunohistochemical expression predicts objective response and cancer-specific survival in patients treated by Cisplatin-based induction chemotherapy for locally advanced head and neck squamous cell carcinoma. Clinical Cancer Research. 2007; 13:3855-3859.

27. Hui EP, Ma BB, Chan KC, Chan CM, Wong CS, To KF, Chan AW, Tung SY, Ng WT, Cheng AC. Clinical utility of plasma Epstein-Barr virus DNA and ERCC1 single nucleotide polymorphism in nasopharyngeal carcinoma. Cancer. 2015; 121:2720-2729.

28. Koh Y, Kim TM, Jeon YK, Kwon TK, Hah JH, Lee SH, Kim DW, Wu HG, Rhee CS, Sung MW. Class III beta-tubulin, but not ERCC1, is a strong predictive and prognostic marker in locally advanced head and neck squamous cell carcinoma. Annals of Oncology. 2009; 20:1414-1419.

29. Shim HJ, Yun JY, Hwang JE, Bae WK, Sang HC, Ji HL, Kim HN, Min HS, Sun SK, Lee JH. BRCA1 and XRCC1 polymorphisms associated with survival in advanced gastric cancer treated with taxane and cisplatin. Cancer Science. 2010; 101:1247-1254.

30. Font A, Taron M, Gago JL, Costa C, Sánchez JJ, Carrato C, Mora M, Celiz P, Perez L, Rodríguez D. BRCA1 mRNA 
expression and outcome to neoadjuvant cisplatin-based chemotherapy in bladder cancer. Annals of Oncology. 2011; 22:139-144.

31. Schmoll HJ, Greene FL, Page DL, Fleming ID, et al (eds). AJCC Cancer Staging Manual, 6th edition. Annals of Oncology. 2003; 14:345-a346.
32. Vilmar A, Garcia-Foncillas J, Huarriz M, Santoni-Rugiu E, Sorensen JB. RT-PCR versus immunohistochemistry for correlation and quantification of ERCC1, BRCA1, TUBB3 and RRM1 in NSCLC. Lung Cancer. 2012; 75:306-312. 